\title{
MODAL ANALYSIS OF DISSIMILAR PLATE METAL JOINING WITH DIFFERENT THICKNESSES USING MIG WELDING
}

\author{
M. M. Hatifi ${ }^{1 *}$, M. H. Firdaus ${ }^{1}$ and A. Y. Razlan ${ }^{2}$ \\ ${ }^{1}$ Advanced Structural Integrity and Vibration Research Group (ASIVR) \\ Faculty of Mechanical Engineering \\ Universiti Malaysia Pahang, \\ 23300 Pekan, Pahang, Malaysia \\ *Email: hatifi@ump.edu.my \\ Phone: +09-4246265 Fax: +09-4244222 \\ ${ }^{2}$ Innovative Manufacturing Design and Processes Expert Group ( $i$-MDP), \\ Faculty of Manufacturing Engineering \\ Universiti Malaysia Pahang, \\ 23300 Pekan, Pahang, Malaysia
}

\begin{abstract}
This paper presents a study of the dynamic behavior of joining hybrid parts, stainless steel and aluminum alloy, by MIG welding. The objective is to analyze the effect of welding on dissimilar plates of stainless steel and aluminum. A finite element model of joining stainless steel and aluminum alloy by welding was built using a structural threedimensional (3D) solid modeling element. Impact testing using hammer excitation and accelerometer response measuring techniques was conducted to measure the vibration properties of the hybrid parts. The natural frequency and the mode shape graph from experimental modal analysis were then compared with the results that were obtained from finite elements (FE) and showed good agreement. Joining welding gives effect to dynamic properties (mode shape) of modal analysis, especially mode 1,3 (bending pattern) and mode 4 (second twisting). The results show significant points about the effect of MIG welding of dissimilar plate in terms of their dynamic properties compared to welding of the same material. Through comparison of the simulation results and the experimental measurements, it can be assumed that, besides the welding-brazing process, other key manufacturing processes such as cladding, buttering and heat treatment should also be taken into account to accurately predict the dynamic properties in the whole range of dissimilar metal joining.
\end{abstract}

Keywords: Modal analysis; welding-brazing; dissimilar plate.

\section{INTRODUCTION}

Dissimilar metal welds are commonly used in nuclear power plants to connect low alloy steel components and austenitic stainless steel piping systems. The integrity assessment and life estimation for such welded structures require consideration of dynamic properties. However, it is very costly and time-consuming to carry out experiments to obtain dynamic properties data. An alternative approach is a computational procedure based on the finite element method, which is effective in solving non-linear problems (Dike, Cadden, Corderman, Schultz, \& McAninch, 1996; Dong, Zhang, \& Li, 1998). Nowadays, metal inert gas welding is an effective technology used throughout the 
industry (Wang et al., 2012). It is used widely in advanced construction and equipment, especially in the automotive industry to join parts. The combination of building materials which commonly uses aluminum and steel is in high demand for welding technology. Joining between aluminum alloys and stainless steel has proved to be significant for the construction industry. Joining between aluminum alloy and steel is also important in the transportation industry, particularly given the need to design lightweight vehicle bodies (Charde, 2012a; Rahman, Arrifin, Nor, \& Abdullah, 2008; Rahman, Rosli, Noor, Sani, \& Julie, 2009; Sakayama et al., 2013; Shah, Akhtar, \& Ishak, 2013). Joining of aluminum and steel by fusion welding is difficult because the compound is a mixture of two substances and forms a brittle intermetallic compound (IMC) in the joints (Charde, 2012b; Thomy, 2012). The joint has two characteristics: on the base, the metal is aluminum alloy with a low melting point, mixed with molten filler metal to form a weld joint, while the surface is steel with a high melting point metal with brazing, which acts like a response with the filler metal melts to form a solder layer interface formed braze joints (Lin, Song, Yang, Fan, \& Zhang, 2010). The joining of aluminum alloy and stainless steel can be difficult for aluminum and nonmetallic iron fusion welding. This is due to the large difference between the melting points $\left(660{ }^{\circ} \mathrm{C}\right.$ for $\mathrm{Al}$ and $1538{ }^{\circ} \mathrm{C}$ for $\left.\mathrm{Fe}\right)$, the close to zero solid solubility of aluminum metal, and the formation of brittle intermetallic compounds. The difference in the thermal properties of the two materials, such as expansion coefficient, conductivity, and specific heat, leads to internal stresses after welding fusion (Song, Lin, Yang, Ma, \& Liu, 2009). Song et al. (2009) said that tungsten arc inert gas (TIG) new weldingbrazing techniques have become a hot research field to participate in an aluminum alloy to stainless steel. In the dynamic arc heating process, the liquid filler metal (aluminum alloy) is not wet and spread on the surface of the steel, although the Al- $\mathrm{Zn}$ coated steel surface can promote the wetting and spreading to fill the metal.

For this project, using metal inert gas welding (Migeon, Texier, \& Pineau, 2000), brazing may produce the same result. The effect of different welding on the joint characteristics of aluminum alloy and stainless steel with MIG welding is shown in Figure 1. The Al-Cu filler metal spreads fully on the steel surface to form a sound joint. The joint has typical welding-brazing dual characteristics: on the aluminum alloy side, the base metal with a low melting point is a welding joint, which mixes with the molten filler metal to form a fusion area, while on the stainless steel side, the steel surface with a high melting point is a brazing joint, which reacts with the molten filler metal to form the brazing interface layer (Borrisutthekul, Mitsomwang, Rattanachan, \& Mutoh, 2010; Wang et al., 2012). The hybrid component has a higher technical and economic potential. The vibration characteristic is a frequent problem that affects the result of joining dissimilar materials such as aluminum alloys and stainless steel by welding. This characteristic is a vital aspect of analyzing and designing structures, especially those that involve dynamic characteristics. Much of the structure of a vehicle body contains welding points, changes in compliance areas welded joints due to fatigue damage that can have a major impact on the nature of the above-mentioned structures (Shang, Barkey, Wang, \& Lim, 2003). The main objective of this investigation is to study the effect of welding-brazing from MIG welding on the vibration characteristics of dissimilar plates with different thicknesses. Finite element modeling was used to find the natural frequencies and mode shapes. Experimental modal analysis will be done to validate the results obtained from $\mathrm{FE}$ analysis. 


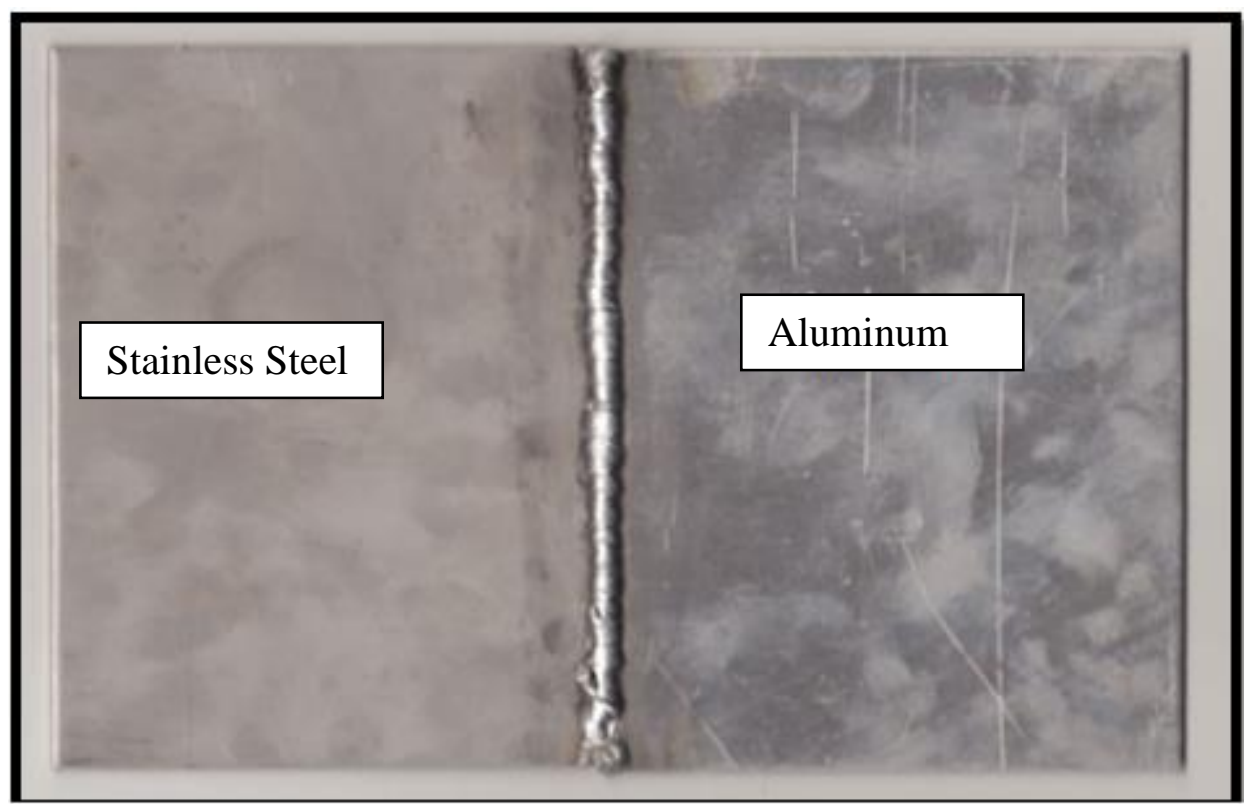

Figure 1. Joining dissimilar plate by MIG welding.

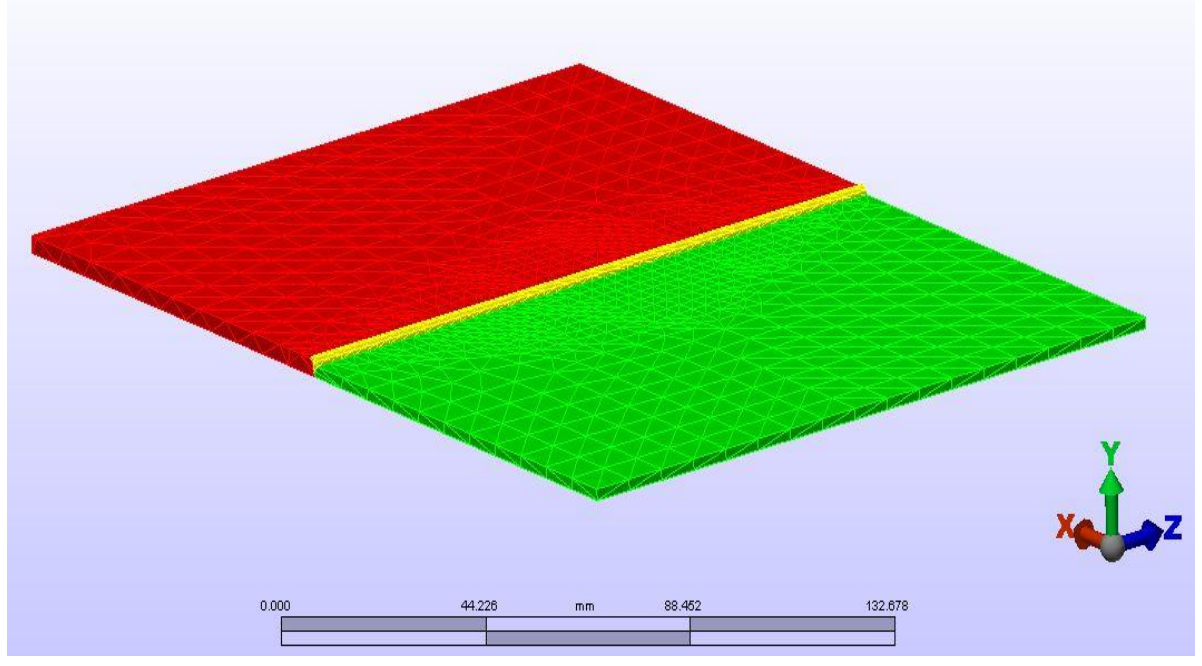

Figure 2. Mesh diagram of assembled parts with weld bead.

\section{FINITE ELEMENT MODELING}

The finite element modeling was carried out in the free-free boundary condition and the mesh was constructed using three parts, representing the aluminum alloy plate, stainless steel plate and weld bead. The element type used for the aluminum alloy plate was aluminum alloy $1100 \mathrm{H} 14$, the stainless steel plate was stainless steel SUS304, and the weld bead was aluminum alloy 4043, as shown in Figure 2. The experiment was carried out by setting the analysis type to Natural Frequency (modal), changing the units from metric mks (SI) to custom unit and changing the length to millimetre $(\mathrm{mm})$ and force to Newton $(\mathrm{N})$. The element definition was set to tetrahedron and the mesh size was defined as $70 \%$. The result is better if a higher percentage of mesh size is set, but a super-computer is then required to perform the analysis (Husain et al., 2010). For this experiment, 30-50 mode shapes were analyzed and no loading or boundary condition 
was imposed on the test specimen. The free boundary condition was simulated by supporting the structure with a soft material such as sponge. The mesh structure for joining the aluminum alloy and stainless steel with weld bead is shown in Figure 2. The simulation was done part by part so that it could be compared to the experimental analysis later. The colors in Figure 2 show the dissimilar materials: red for aluminum, green for stainless steel, and the yellow between the red and green shows the weld bead.

\section{EXPERIMENTAL MODAL ANALYSIS}

Experimental tests were designed in order to measure the natural frequency and mode shape of the hybrid plates with MIG welding for comparison with FEM results. The joining between aluminum alloy and stainless steel was done using metal inert gas (Migeon et al., 2000) welding, as shown in Figure 3, before conducting the experimental modal analysis. In this figure, the left side is stainless steel and the right side is aluminum alloy and these were joined using metal inert gas with a welding current of $252 \mathrm{~W}$ and speed of $18 \mathrm{~m} / \mathrm{min}$ (Migeon et al., 2000). The figure shows the appearance of the aluminum-steel butt joint made by MIG welding-brazing. It was observed that the joint has a good front and back and no crack appears on the welded seam/steel interface. The flux slag carpets on the half surface of the welded seam on the steel side due to its low gravity, and the residual flux deposits on the steel surface near the welded seam.

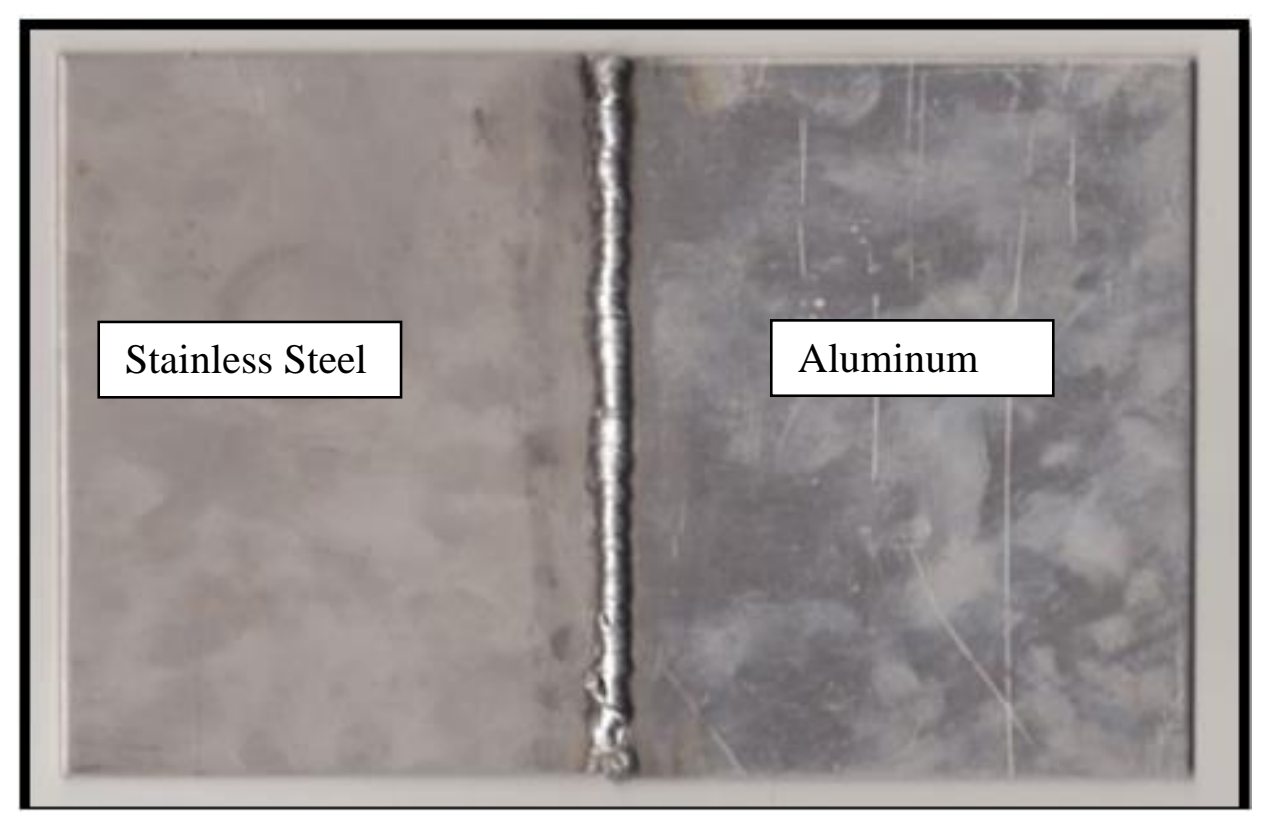

(a)

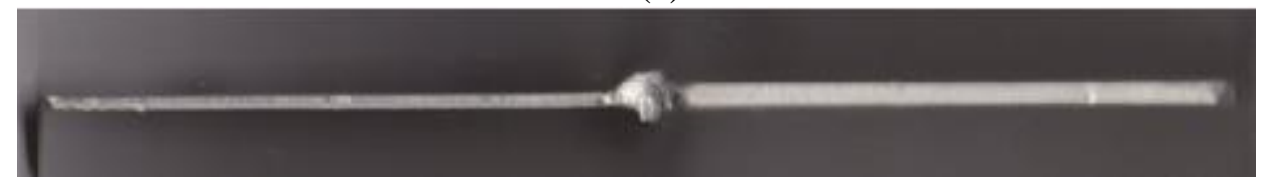

(b)

Figure 3. Joining plate by MIG welding: (a) front view; (b) side view

Figure 3(b) shows the molten steel flow and the fracture that occurred at the root interface seams / welded steel after welding with a high heat input. It shows the typical 
cross-section of the aluminum-steel butt joint. The stainless steel plate is $2 \mathrm{~mm}$ thick, while the aluminum plate is $3 \mathrm{~mm}$ thick. The $\mathrm{Al}-\mathrm{Cu}$ filler metal spread fully on the steel surface to form a sound joint. The joint has typical welding-brazing dual characteristics: on the aluminum alloy side, similar to Song's research in terms of technique, the base metal with a low melting point is a welding joint, which mixes with the molten filler metal to form a fusion area, while on the stainless steel side, the steel surface with a high melting point is a brazing joint, which reacts with the molten filler metal to form the brazing interface layer.

In the experiment, an impact hammer was used to run experimental modal testing on the $\mathrm{Al}-\mathrm{Cu}$ joint. The component was interfaced with a host computer, allowing for coordination of the operation of the overall system and enhancing the data processing capabilities. An impact hammer test is the most common method of measuring FRFs (frequency response functions). (Herlufsen, 1984; Ramsey, 1983). The hammer impacts a transient impulsive force excitation to the dissimilar plate. The impact is intended to excite a wide range of frequencies so that the DAQ (data acquisition system) can measure the vibration of the device across this range of frequencies. In the experiment, an accelerometer was used and was connected to the DAQ. The accelerometer is a device for measuring the vibration of a structure, producing an output signal proportional to the acceleration. It works by having some kind of force measuring sensor with a mass attached to it so that when the dissimilar plate is forced to vibrate, a force proportional to acceleration will be produced. The dynamic force signal is recorded by the DAQ. After the impact, the dissimilar plate vibration was measured with the accelerometer and recorded by the DAQ, and the data was transferred to the computer and the FRF was obtained by comparing the force excitation and the response acceleration signals. Figure 4 shows an experimental setup for a measurement system with tags numbered 1 to 5 . Tag number 1 is the impact hammer, 2 is the triaxial accelerometer, 3 is the NI DAQ, 4 is the laptop and 5 is the dissimilar plate.

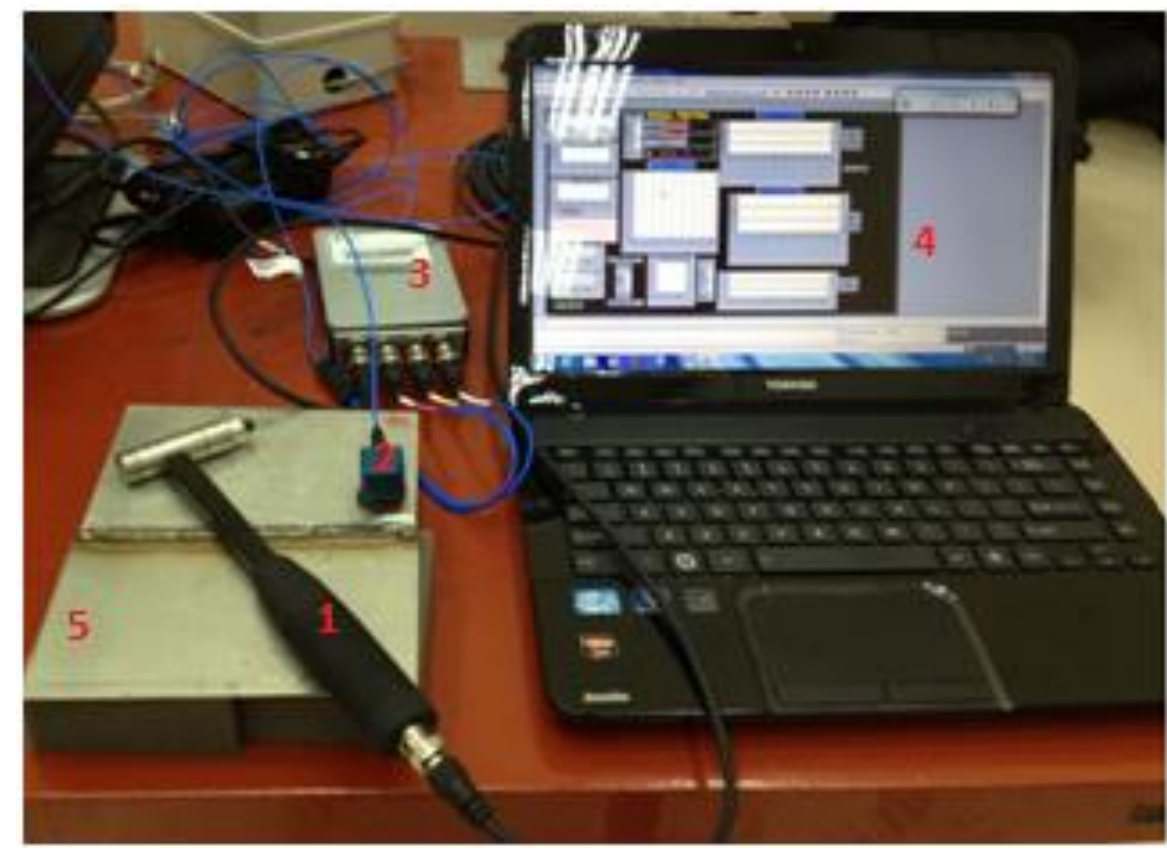

Figure 4. Experiment modal analysis setup 


\section{RESULTS AND DISCUSSION}

\section{Natural Frequencies}

In order to clarify the results that were obtained from this research, results from the experimental and numerical analysis were compared according to the impact on the welding of the dissimilar plate. Table 1 shows the natural frequencies obtained from the finite element models and experimental modal testing when joining aluminum alloy and stainless steel with a weld, and the percentage of error in the different cases. Mode shape 5 had the lowest percentage error while mode 2 had the highest percentage error.

Table 1. Comparison of natural frequency analysis between FEA and experimental modal analysis.

\begin{tabular}{cccc}
\hline $\begin{array}{c}\text { Mode } \\
\text { shape }\end{array}$ & Theoretical & Experimental & Error $(\%)$ \\
\hline 1 & 839.676 & 792 & 5.678 \\
2 & 1043.93 & 1120 & 7.287 \\
3 & 1848.8 & 1940 & 4.933 \\
4 & 2605.52 & 2490 & 4.434 \\
5 & 2935.05 & 2940 & 0.169 \\
\hline
\end{tabular}

Figure 5 shows the frequency of finite element models and the experimental modal testing of the joining plate between aluminum alloy and stainless steel. All the points that were struck by the hammer resemble each other. This shows that the objects were designated with a certain natural frequency that differed only slightly with distance; the distance was measured from both ends, which means that the value of frequency at one end is the same as at the other end and is the same as any other point that is mirrored on the other side.

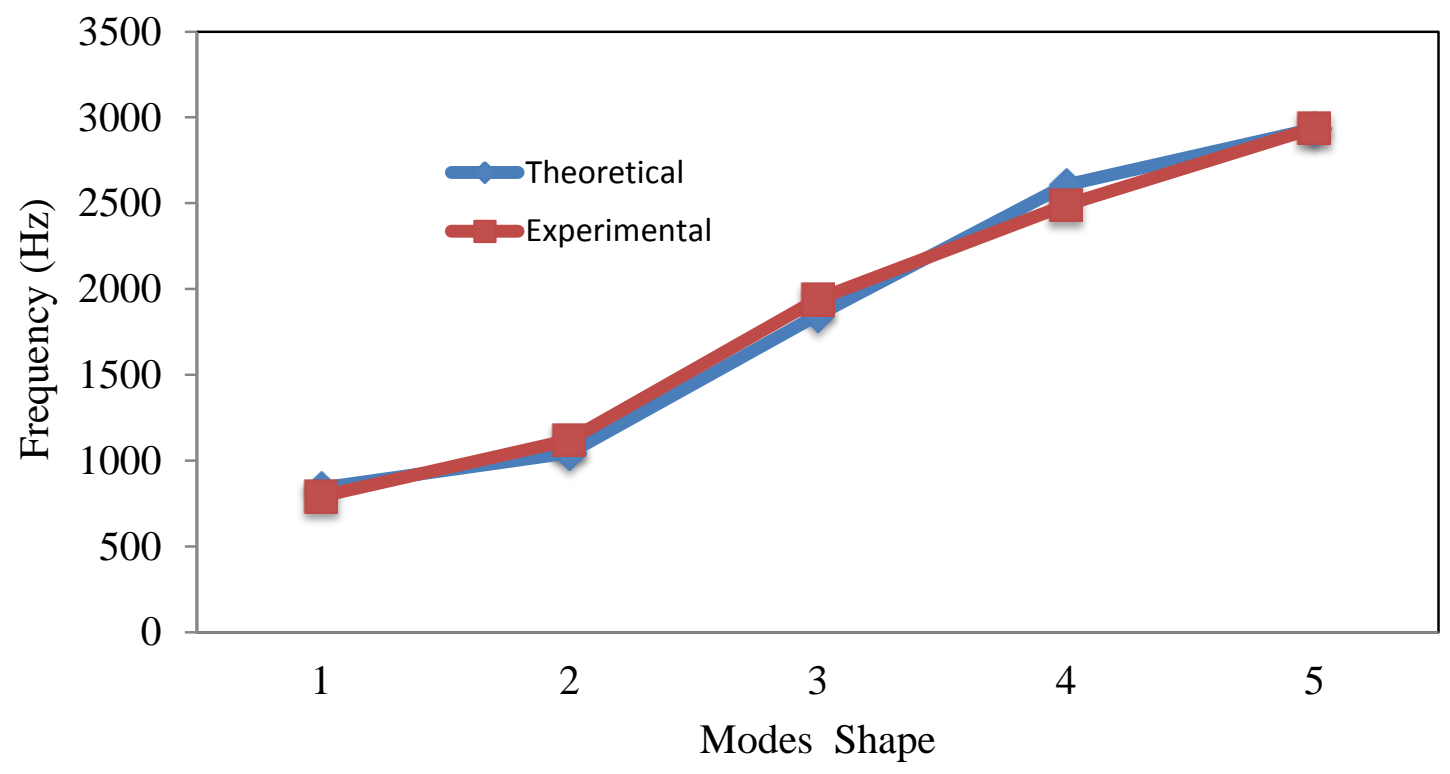

Figure 5. Comparison of natural frequency analysis. 
Although the differences are small, it is clear that the highest natural frequency is gained with mode 5. Both the numerical and experimental results indicate that the inclusion of residual stresses when joining dissimilar metals tends to raise the natural frequency, as these stresses are mainly tensile in nature, thus increasing the lateral stiffness of the plates, leading to an increase in natural frequency. The increase in natural frequency due to residual stresses is small because these stresses are acting on small areas (Society) relative to the area of the plate.

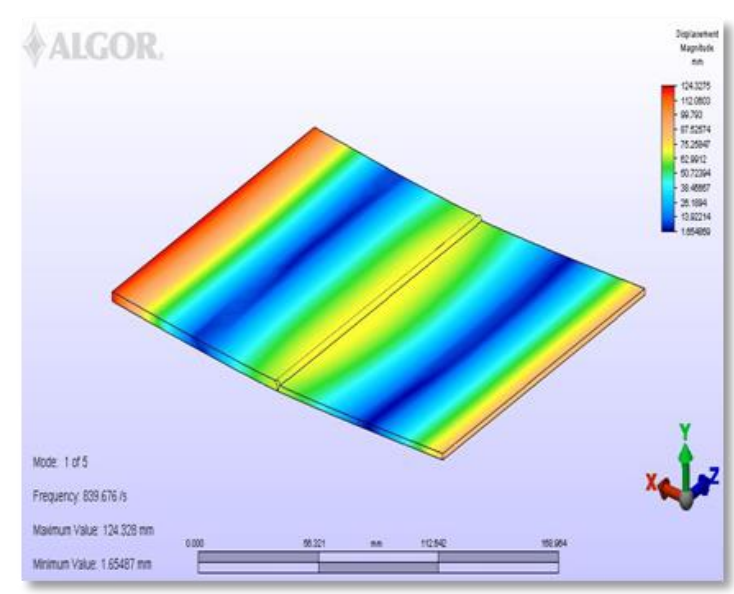

(i)

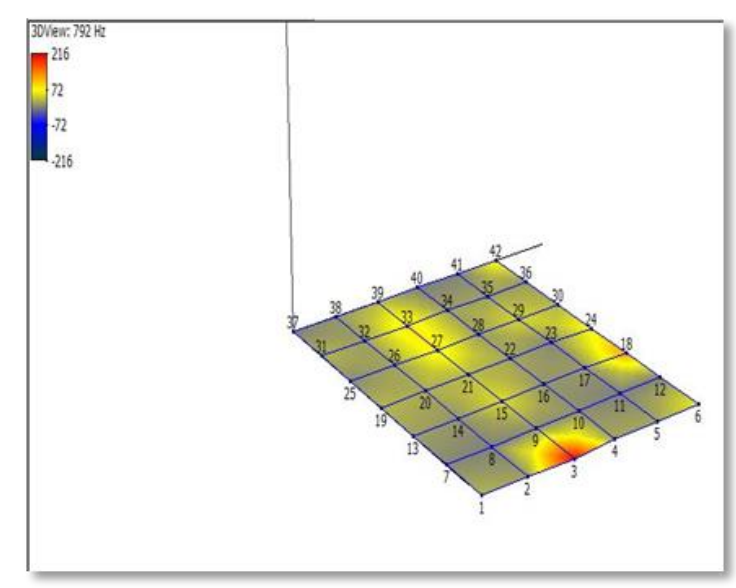

(ii)

(a)

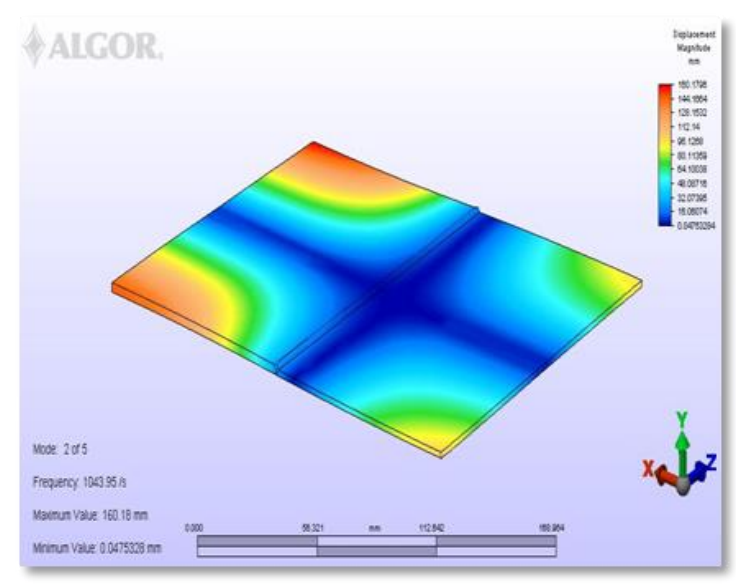

(i)

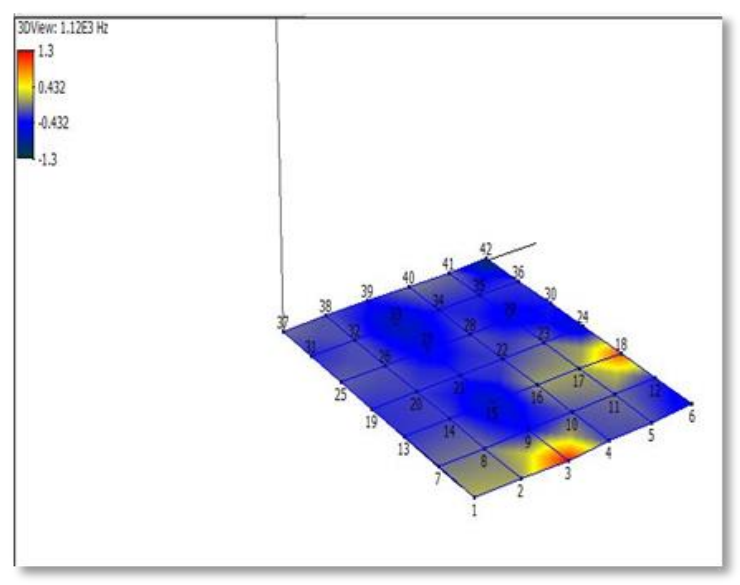

(ii)

(b)

Figure 6. Numerical (i) and experimental (ii) analysis of mode shapes when joining dissimilar plates by MIG welding: (a) Mode 1; (b) Mode 2. 


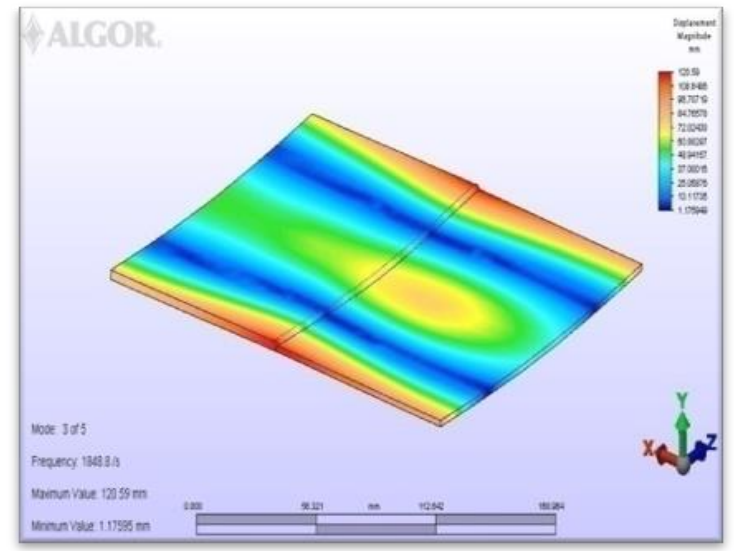

(i)

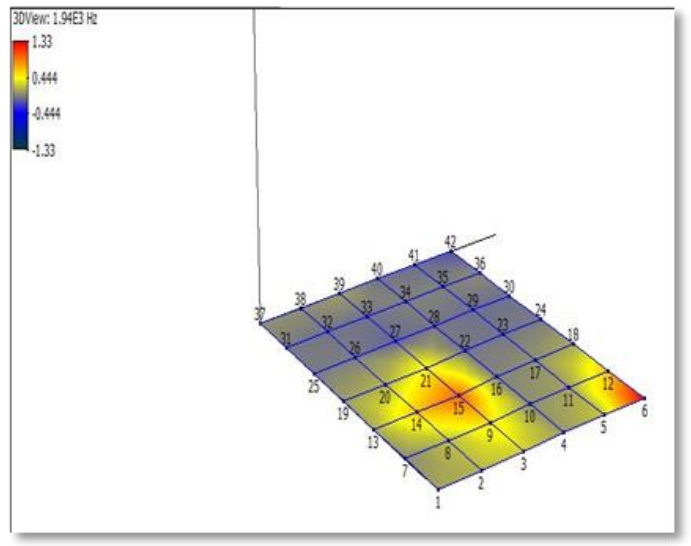

(ii)

(c)

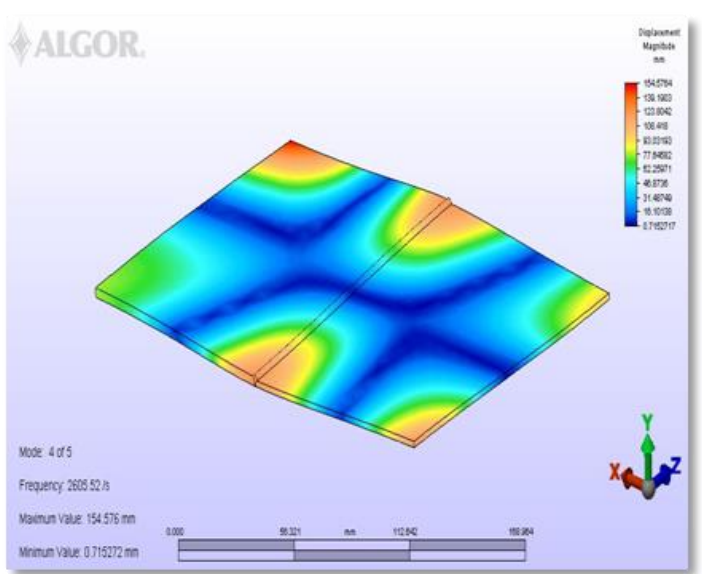

(i)

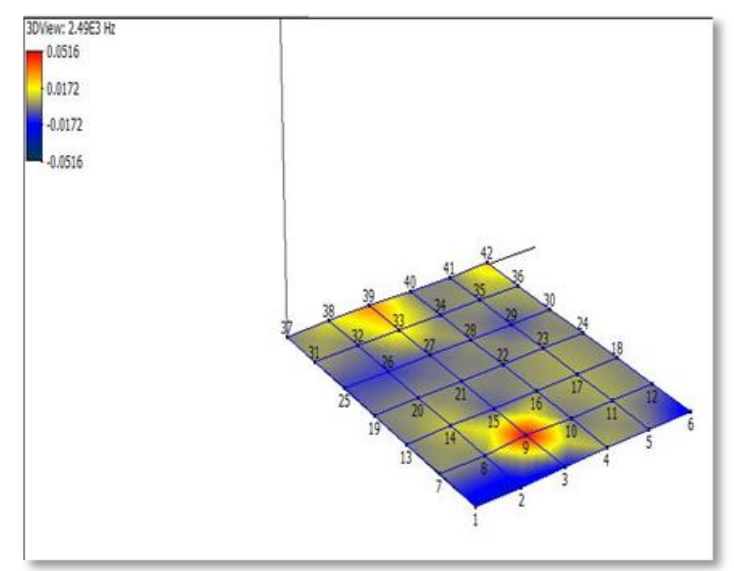

(ii)

(d)

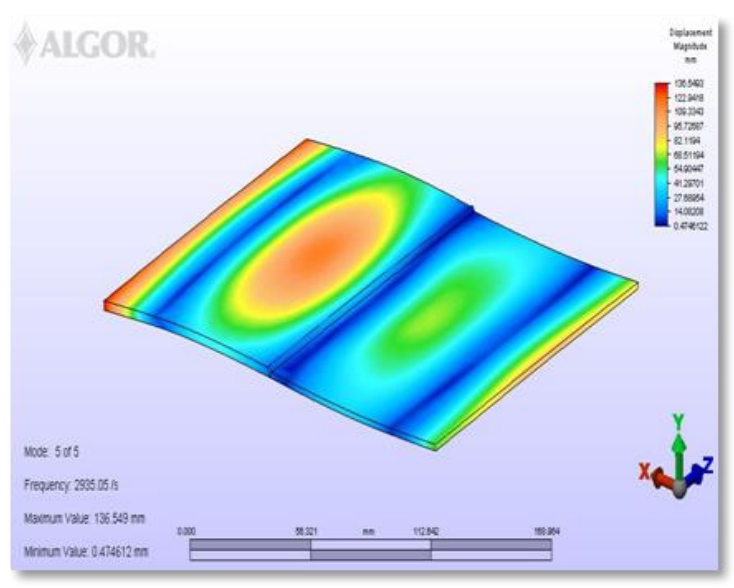

(i)

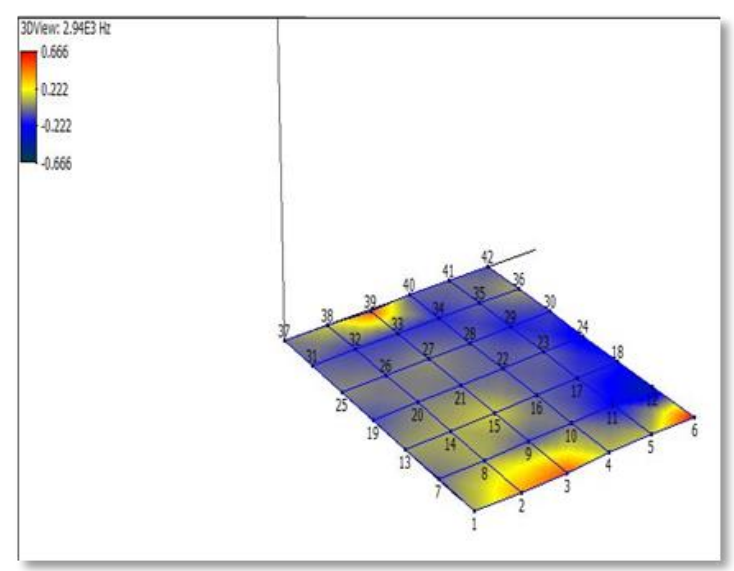

(ii)

(e)

Figure 7. Numerical (i) and experimental (ii) analysis of mode shapes when joining dissimilar plates by MIG welding: (c) Mode 3; (d) Mode 4; (e) Mode 5. 


\section{Mode Shapes}

Mode shapes are deformation patterns of resonant frequencies and a variety of different deformation shapes were produced, depending on the excitation force frequency. These deformation patterns are referred to as the structure's mode shapes. From the experimental analysis, a set of data was collected during the impact hammer testing. The testing was made at 42 points selected at the joining plate between the aluminum alloy and stainless steel, consisting of 18 points in the aluminum alloy area, 18 points in the stainless steel area and 6 points in the welded area. Point numbers 1 to 24 represented the aluminum plate and points 19 to 42 represented the stainless steel plate. Numerical analysis was done by finite element analysis (FEM) and was compared to the experimental results for the mode shapes. This pattern deformation is referred to as the mode shape structure. That is actually not perfectly correct from the standpoint of pure mathematics, but for a brief discussion here, this pattern of deformation is very close to the mode shapes from a practical point of view. Figure 6 and 7 show the five mode shapes when joining dissimilar plate aluminum alloy and stainless steel by welding. The figure compares every mode shape from the numerical analysis (i) with that from experimental analysis (ii). There is a second bending deformation pattern for mode 5 . The red color indicates the maximum displacement that occurred in the mode and the blue color is the minimum displacement. The mode shapes obtained numerically and experimentally are almost identical. The maximum difference in natural frequency ocurred in the second mode, with a value of $7.287 \%$, which is almost acceptable. The natural frequencies obtained experimentally and numerically are verified to be in good agreement, since the maximum difference occurred in the range of $4.5 \%$. This is a good proof for the validity of the experimental and numerical frequency expressions.

\section{CONCLUSIONS}

In this research on joining stainless steel and aluminum alloy using MIG welding, the results are similar to those of the study by Song et al. (2009), which showed that welding by MIG will produce welding-brazing joining because of the different melting points. Referring to the results obtained, it can be seen that the numerical and experimental results showed good agreement. It was found that the residual stresses produced in each piece have a significant effect on the natural frequency of the dissimilar plate, where the natural frequency increases when residual stresses are included. Joining by welding-brazing affects the dynamic properties (mode shape) in the modal analysis, especially modes 1 and 3 (bending pattern) and mode 4 (second twisting).

\section{ACKNOWLEDGMENT}

This work was sponsored by the Univerisity Malaysia Pahang, Kuantan, Malaysia under grant number RDU 110316.

\section{REFERENCES}

Borrisutthekul, R., Mitsomwang, P., Rattanachan, S., \& Mutoh, Y. (2010). Feasibility study of using tig welding in dissimilar metals between steel/aluminum alloy. Energy Research Journal, 50(2), 82-86. 
Charde, N. (2012a). Characterization of spot weld growth on dissimilar joints with different thicknesses. Journal of Mechanical Engineering and Sciences, 2, 172180.

Charde, N. (2012b). Effects of electrode deformation of resistance spot welding on 304 austenitic stainless steel weld geometry. Journal of Mechanical Engineering and Sciences, 3, 261-270.

Dike, J., Cadden, C., Corderman, C., Schultz, C., \& McAninch, M. (1996). Finite element modeling of multi-pass gma welds in steel plates. Paper presented at the International Trends in Welding Research, , Materials Park, Ohio.

Dong, P., Zhang, J., \& Li, M. (1998). Computational modeling of weld residual stresses and distortions-an integrated framework and industrial applications. ASMEPUBLICATIONS-PVP, 373, 311-336.

Herlufsen, H. (1984). Dual channel fft analysis part 1 \& 2. . In Kjær, B. (Ed.), Technical Review No. 1 \& 2. BV 0013-11 \& BV 0014-11. .

Husain, N. A., Khodaparast, H. H., Snaylam, A., James, S., Dearden, G., \& Ouyang, H. (2010). Finite-element modelling and updating of laser spot weld joints in a tophat structure for dynamic analysis. Proceedings of the Institution of Mechanical Engineers, Part C: Journal of Mechanical Engineering Science, 224(4), 851861.

Lin, S., Song, J., Yang, C., Fan, C., \& Zhang, D. (2010). Brazability of dissimilar metals tungsten inert gas butt welding-brazing between aluminum alloy and stainless steel with al-cu filler metal. Materials \& Design, 31(5), 2637-2642.

Migeon, C., Texier, A., \& Pineau, G. (2000). Effects of lid-driven cavity shape on the flow establishment phase. Journal of Fluids and Structures, 14(4), 469-488.

Rahman, M. M., Arrifin, A. K., Nor, M. J. M., \& Abdullah, S. (2008). Fatigue analysis of spot-welded joint for automative structures. SDHM Structural Durability and Health Monitoring, 4(3), 173-180.

Rahman, M. M., Rosli, A. B., Noor, M. M., Sani, M. S. M., \& Julie, J. M. (2009). Effects of spot diameter and sheets thickness on fatigue life of spot welded structure based on fea approach. American Journal of Applied Sciences, 6(1), 137-142.

Ramsey, K. A. (1983). Experimental modal analysis, structural modifications and fem analysis on a desktop computer. Paper presented at the 1st International Modal Analysis Conference Proceedings, Orlando, Florida.

Sakayama, T., Naito, Y., Miyazakki, Y., Nose, T., Murayma, G., Saita, K., \& Oikawa, H. (2013). Dissimilar metal joining technologies for steel sheet and aluminum alloy sheet in auto body. Nippon Steel Tech. Rep, 103, 91-98.

Shah, L. H., Akhtar, Z., \& Ishak, M. (2013). Investigation of aluminum-stainless steel dissimilar weld quality using different filler metals. International Journal of Automotive and Mechanical Engineering, 8, 1121-1131.

Shang, D.-G., Barkey, M. E., Wang, Y., \& Lim, T. C. (2003). Effect of fatigue damage on the dynamic response frequency of spot-welded joints. International Journal of Fatigue, 25(4), 311-316.

Structural welding code-steel (2004).

Song, J. L., Lin, S. B., Yang, C. L., Ma, G. C., \& Liu, H. (2009). Spreading behavior and microstructure characteristics of dissimilar metals tig welding-brazing of aluminum alloy to stainless steel. Materials Science and Engineering: A, 509(1), $31-40$. 
Thomy, D.-I. C. (2012). Laser-mig hybrid welding of aluminium to steel-effect of process parameters on joint properties. Welding in the World, 56(5-6), 124-132.

Wang, J., Lu, M. X., Zhang, L., Chang, W., Xu, L. N., \& Hu, L. H. (2012). Effect of welding process on the microstructure and properties of dissimilar weld joints between low alloy and duplex stainless steel. International Journal of Minerals, Metallurgy and Materials, 19(6), 518-524. 